\title{
Librarians' Perceptions of the Challenges for Researchers in Rwanda and the Potential of Open Scholarship
}

https://doi.org/10.1515/libri-2020-0036

Published online February 17, 2021

\begin{abstract}
Open scholarship is a major reform movement within research. This paper seeks to understand how open scholarship might address the challenges faced by research in Africa, through a study based on a participatory collaborative workshop to create a partnership with librarians in Rwanda. The literature review identifies three broad perspectives on the apparent underperformance of Rwandan research: one locating the issue in the unequal scholarly communications system, a second pointing to a country deficit and a third blaming cognitive injustices. The Rwandan librarians see researchers as challenged through the pressures on them to publish, the costs of research, poor infrastructure, lack of skills and limited access to literature. Collectively these challenges constitute a critical barrier to research. These limits fit largely the country deficit perspective. Open scholarship as conceived in the Global North is only a small part of the answer to the challenges faced by Rwandan scholars. To promote equity, notions of open scholarship need to take into account the conditions under which research is conducted in less privileged contexts such as Rwanda.
\end{abstract}

Keywords: open scholarship, open science, open research, open access, epistemic injustice, Rwanda

\section{Introduction}

Open scholarship is an important new development in the governance and practice of research. Originating in the Global North, it seems to contain a number of different arguments or discourses, but as an idealistic movement to reform science, we would expect it to address

*Corresponding author: Andrew Cox, Information School, University of Sheffield, Sheffield, UK, E-mail: a.m.cox@sheffield.ac.uk. https://orcid.org/0000-0002-2587-245X

Pamela Abbott, Information School, University of Sheffield, Sheffield, UK. https://orcid.org/0000-0002-4680-0754 inequities in how science works and improve opportunities for all scholars. One key inequity is the low visibility of African research. Many authors quote the statistic that sub-Saharan Africa produces less than $1 \%$ of the world's research output at least measured by Web of Science (e.g. Fonn et al. 2018; Malapela 2017). There are a number of types of explanations of this in the literature, which we will suggest below centre around three perspectives: one located in the inequities in the scholarly communication system, another focussing on deficits in the in-country research environment and a third more trenchant, potentially transformative perspective that locates the problem in cognitive injustices arising from continuing neo-colonialism. A number of authors are optimistic that open scholarship offers at least part of the answer to addressing these challenges (e.g. Piron, Regulus, and Djiboune Madiba 2016; Raju, Adam, and Powell 2015). The purpose of this paper is to consider the potential impact of open scholarship for enhancing the success of research in the Global South, in the context of such barriers, by focussing on a specific example, the country of Rwanda. It uses data gathered from a participatory collaborative workshop with Rwandan librarians to explore their perception of these issues and on that basis consider the potential for open scholarship. Specifically, it seeks to answer two research questions:

(1) What are Rwandan librarians' perceptions of the challenges for research in their country?

(2) How is open scholarship relevant to addressing these challenges?

The paper makes a contribution to the Library and Information Sciences (LIS) literature in three ways. First, it identifies three major perspectives in the literature explaining the apparent under-performance of African research (without assuming that this is real). Second, it advances our understanding of the challenges in the research environment in Rwanda, from Rwandan librarians' point of view, the first such published output to do so. Third, it shows through the example of Rwanda that the definition of open scholarship needs to be shaped by contextual needs, in a way that current definitions, developed for Global North contexts, do not. 


\section{Literature Review}

\subsection{Open Scholarship}

There is currently intense interest in policy and practice in the Global North around the concept of open science or, more broadly, open scholarship, the term we prefer in this paper (Lasthiotakis, Kretz, and Sa 2015). At the simplest level this is about the open sharing of resources and ideas, yet what the concept means is still contested, partly because of the ambiguity of the term "open” (Levin et al. 2016).

One starting point for understanding open scholarship is to consider the definition and justification offered in the major report by the US National Academies of Sciences, Engineering and Medicine (2018), Open science by design. This report defines open science's "ambitious" goal as to "ensure the availability and usability of (1) scholarly publications, (2) the data that result from scholarly research and (3) the methodology including code or algorithms that was used to generate those data." (National Academies of Sciences, Engineering and Medicine 2018, 19). According to the report, the benefits of such openness include ensuring rigour and reliability of research, increasing the speed and reach of dissemination, broadening participation in research and better resource usage. Acknowledged barriers are the costs and infrastructure needs, the current scholarly communications system, lack of the appropriate cultures various privacy or security issues and disciplinary differences.

Key to the concept of open scholarship is that it includes but extends beyond open access in the sense of open sharing of research outputs. The definition in the report emphasises three elements: open access to outputs, open data and open code. But to illustrate the ambiguity of the open scholarship concept, Raju, Adam, and Powell (2015) also refer to three pillars, but they are slightly different: open access to papers, open-source software and open educational resources. Masuzzo and Martens (2017) refer to open science having four pillars, namely open access to papers, open code, open data and open peer review. Other accounts suggest the need to refer to a significantly wider range of open practices, such as open workflows (Vicente-Sáez and Martínez-Fuentes 2018). Vicente-Saez and Martinez-Fuentes (2018) seek to solve the problem of multiple definitions of open science by a systematic literature review and conclude by proposing a high-level definition as follows: "open science is transparent and accessible knowledge that is shared and developed through collaborative networks" (434). This is coupled with a diagram that identifies and connects together a number of features or practices of open science, namely: "open access, data-intense, alternative reputation systems, open notebooks, open lab books, science blogs, collaborative bibliographies, citizen science, open peer review, pre-registration, open code and open data". This is useful in capturing the spirit of the movement, but also identifying a wide range of specific practices that instantiate it, some less obviously related to openness, such as the stress on data-intensity.

An alternative approach to the complexity of the concept is adopted by Fecher and Friesike (2013) who suggest that there are five different schools of thought around open science, namely:

(1) A democratic school that seeks to make the products of research freely available to everyone,

(2) A pragmatic school which seeks to make science more efficient by opening up the process of knowledge creation,

(3) An infrastructural school focussed on the technical challenge of creating tools and applications to enable scientists to share,

(4) A public school that seeks to make science more accessible to citizens, and

(5) A measurement school seeking to develop alternative metrics to measure scientific quality.

This approach has the virtue of acknowledging differing drivers and ideologies, rather than trying to mask them behind a single synthesised definition. Thus, part of the driver for open scholarship seems to be a concern with the right to access to knowledge: outputs and data should be open so that all researchers or all citizens should have access to knowledge. In a slightly different emphasis, another driver is to connect the public back into science through active participation, e.g. as in citizen science. Another driver is a concern with research integrity and the need to ensure reproducibility, e.g. through making data and code more reusable. Another driver is more around the new research made possible if outputs, data and code are shared. Often the arguments are presented as one, but they are actually pulling in different directions and can be assembled in different ways. Fecher and Friesike's (2013) approach is useful in revealing this more clearly.

Much of the rhetoric around open scholarship, as in open access before it, revolves around the equity and integrity of scholarship but it rarely engages explicitly with the issues challenging research in the Global South. Many policy documents stress the value to competitive advantage or growth; few mention its contribution to sustainability (Albornoz et al. 2018). One of the few exceptions is the work of OCSDnet in developing a concept of "open and collaborative science" (Albornoz et al. 2018; Hillyer et al. 2017). Their definition of open science, in a seven-point 
manifesto, emphasises openness as a collaborative approach, to be negotiated locally relative to local conditions (Albornoz et al. 2018; OCSDnet n.d). This is a very powerful starting point for querying the nature of open scholarship, stressing the need for "equitable collaboration" and "inclusive infrastructures". Although intended to specifically address the issues for development studies, it is more generally useful in recognising how the principles of open scholarship as understood in the Global North need to be rethought for the Global South.

In this paper we want to further explore whether and how open scholarship can help in addressing the inequities that appear to hold back African scholarship. As the basis for this, it is necessary to clarify what seems to be causing the apparent failure of African scholarship. In the following sections we identify three perspectives on this failure.

\subsection{Open Scholarship and Inequalities in the Scholarly Communication System Perspective}

One perspective on the apparent underperformance of African research is to locate the problem firmly in the structure of the scholarly communication system as currently constituted. This system is dominated by a number of powerful commercial publishers based primarily in the USA and UK, publishing in English. Run on a forprofit basis, their journals are expensive to license and the costs have historically spiralled upwards. Even wealthy institutions in the Global North have increasingly struggled to afford to pay for access. There is a sophisticated bibliographic infrastructure that permits users to find literature in these journals. The impact factor system privileges citation within this same network of journals. Material published outside the system is almost invisible and so effectively has no impact (as measured through citations).

The way the publishing industry works places authors in the Global North in a powerful position to dominate academic knowledge. The research agenda is set by issues defined in the Global North, so that, for example, diseases common in high income countries are researched much more than those prevalent in the South (Gwynn 2019). A large proportion of papers published about the Global South are not co-authored by someone from the Global South (Boshoff 2009). Even in a topic like ICT4D, it is the voice of authors from the Global North that dominate (Bai 2018; Okune et al. 2016).

Some aspects of the inequities in the scholarly communication system are addressed by open scholarship. For example, a major strand in open scholarship remains open access through editorial roles in English language journals. Making the outputs of research openly available, for no charge, should enable anyone, in theory, including researchers in the Global South, to access the latest ideas and so increase their ability to participate in the most up to date research. Open research data in theory would parallel this, in giving access to scholars in the Global South datasets produced in the Global North. Open peer review might give new ideas greater chance of being published (Schmidt et al. 2018). New forms of impact measurement like Altmetrics displace dependence on the flawed system of citation metrics, because they widen the range of measures of article popularity.

Open scholarship seems to address many of the key issues with the current scholarly communication system, though probably not all. For example, it assumes that everyone has a network connection and the digital skills to locate and use open material. In reality, given the greater scale of research in the Global North, openness could reinforce its dominance. Scholars in the Global North could use their infrastructural advantages to access and exploit data produced in the Global South (Serwadda et al. 2018). Further, there are certainly other problematic aspects of the scholarly communication system that do not seem to be addressed via open scholarship as it is usually understood. Because of the dominance of English as the language of science, like other non-native English speakers, African scholars have to struggle to present their ideas in another language. The language of science being English can be seen as "linguistic imperialism" (Canagarajah 2002; Phillipson 1992). This is another issue that open scholarship does not directly address.

\subsection{The Country Deficit Perspective}

An alternative perspective on the apparent low development of research in sub-Saharan Africa could be dubbed the country deficit perspective. This places centre stage a web of in-country issues which inhibit research (Atuahene 2011). Different accounts within this perspective have somewhat different emphases: it can be seen as a failure of investment by governments or a lack of support and incentives for researchers, or as arising from weakly developed infrastructures. But it seems to be a pattern recognisable across sub-Saharan Africa, as case studies of countries such as Tanzania show (Fussy 2018). Rather than focussing on the inequalities created by the international scholarly communication system it focuses on the way that a less developed internal environment for research makes it hard to perform equally. 
One central issue in the country deficit perspective is that state commitment to and investment in research in Africa is low. Investment in education including higher education was a priority immediately after independence (Fonn et al. 2018). But since the 1980s governments have reduced spending on education and research. This was reinforced by economic policies imposed via the International Monetary Fund (IMF). Investment has increased a little since the World Bank recognised the need to create local knowledge economies in Africa (Collins and Rhoads 2010; Fonn et al. 2018). As a result, Africa's contribution to research output has grown slightly (Fonn et al. 2018). Yet the level of government investment in research remains low, compared to Western countries, typically at below $0.5 \%$ of GDP (Beaudry, Mouton, and Prozesky 2018). Research policies tend to mimic those of the Global North, ignoring local conditions (Boshoff 2009). Universities neglect research: rather their strategy is massification, so there has been a growth of student numbers, with accompanying pressures on academics' workload reducing the time to do research (Beaudry, Mouton, and Prozesky 2018).

With universities' focus on teaching, there is a lack of inspiration for research as a career (Ngongalah et al. 2019). Lack of funding, equipment and support and mentoring are key barriers for young scholars (Beaudry, Mouton, and Prozesky 2018). Teaching in research methods is missing (Ngongalah et al. 2019). The lack of influence of research on policy further reduces the motivation to undertake research. There is often also a paucity of the free expression in society as a whole that could be seen as a precondition for scientific debate. The low rewards for research and absence of a research environment has led to a brain drain, with many talented individuals being drawn to migrate (Ondari-Okemwa 2007). The proportion of scholars moving away from Africa could have been as much as $30 \%$ in the 1980s and 90s (Beaudry, Mouton, and Prozesky 2018).

Another important issue in the country deficit model is basic infrastructure. There are fundamental problems in terms of reliable electricity supply, computer ownership, Internet access and bandwidth. Even within universities, which are relatively well resourced, facilities lag behind those in the Global North. As well as the international inequities, there are significant differences in access to resources and skills between institutions, between subject areas of study and geographically within countries (Gwynn 2019). Women are under-represented in scholarly output (Gwynn 2019). While considerable investment is being made in Internet infrastructure and digital skills (Nwagwu 2013), African infrastructure consistently lags behind that taken for granted in the Global North.
There are some connections to be made to the scholarly communications perspective. Low investment in research as a whole is reflected in a failure to license access to relevant literature. Even where access is available, e.g. through open access, scholars often lack the bandwidth or digital and information literacy skills to access the content. The same applies to barriers to publishing work from Africa. The gold open route is not affordable given the low funding of African research. In terms of green open access, it has proved hard to maintain the repository infrastructure. Dlamini and Snyman (2017) identify the main perceived reasons why open access repositories are not well developed in Africa as lack of funding, awareness and support from senior management and poor technical infrastructure. Not that all these problems are unique to Africa, but the barriers do mean that Africa lags significantly behind the Global North. Fundamentally, the relatively under-resourced research environment makes it hard for scholars in sub-Saharan Africa to benefit from this aspect of open access.

At the same time, scholarly publishing within Africa itself is not well developed compared to countries in the Global North partly because of a lack of sustainable business models or funding. African authors are reluctant to publish in local journals because the journals lack prestige; indeed for tenure African institutions tend to require publication in "international journals" with impact factors. Local publications are effectively invisible since they are not effectively indexed within scholarly communication systems. Language is also particularly a barrier for scholars from sub-Saharan Africa: there are many local languages, but few are used for research publication (Ondari-Okemwa 2007). Scholars in Europe working outside English at least have some journals in their own native language to publish in and some of these are included in the commercially based scholarly communication system. This is virtually non-existent for African languages.

In the realm of the sharing of research data, Bezuidenhout et al. (2017) identify a large number of barriers to research in low resourced research environments. Researchers in Sub-Saharan Africa have a catalogue of concerns about data sharing (Bezuidenhout 2019; Bezuidenhout and Chakauya 2018), many of which echo those raised by scholars in the Global North (Borgman 2012). However, being relatively disadvantaged in terms of the whole infrastructure, they are always at a disadvantage for gaining from data sharing. The cost of hardware and software, slow Internet speeds and lack of technical support are daily challenges that create an insidious form of inequality, rarely considered by authors from the Global North writing about data sharing. Because of time 
constraints African scholars work relatively slowly: the fear of being scooped that other scholars express is even more of a danger for them. Scholars are positive about sharing data, but worried because data collected was using out of date software. There is a lack of awareness and use of opensource software (Vermeir et al. 2018). The evidence also suggests that outside South Africa library support services to Research Data Management (RDM) are little developed in the region (Chiware and Becker 2018). Bezuidenhout et al. (2017) conclude that the accumulation of obstacles and inequities creates a huge relative disadvantage.

There are, it should be emphasised, some positive trends and initiatives in this context. There has been a significant increase in investment in African research in the last decade, driven by an effort to create knowledge economies, and resulting in increasing academic output (Arvanitis and Mouton 2019; Molla and Cuthbert 2018). Africa's share of global scientific output has risen to above $3 \%$ according to some authors (Arvanitis and Mouton 2019). Specifically in relation to information access, Internet connectivity is improving as is the level of digital skills (Nwagwu 2013). Attempts have also been made to stimulate library consortia purchasing. Other initiatives revolve around providing more robust, visible platforms for locally edited journals: e.g. African Journals Online (AJOL). Some American universities are making an effort to produce metadata on locally produced publications to make them more visible. But a large relative disadvantage continues to exist, arising from patterns of government investment, the pressures of teaching and gaps in infrastructure.

How might open scholarship help address such issues? Looked at from the country deficit perspective, open scholarship does not offer a strong solution to the underlying issues around the governance, funding and support infrastructure for research. Further, as Bezuidenhout et al. (2017) argue, the model of open scholarship is often premised on typical conditions for research in the Global North as being normal, masking the impact of multiple levels of disadvantage.

\subsection{The Cognitive Injustices Perspective}

A third perspective can be seen emerging which encompasses the scholarly communication system and country deficit perspectives, but locates the fundamental issue in neo-colonialism and the diminution, even erasure, of African ways of knowing within human knowledge systems dominated by the Global North. We follow Mboa Nkoudou (2016) and Piron, Regulus, and Djiboune Madiba (2016) in labelling this the cognitive injustices perspective.
Nyamnjoh's (2012) analysis traces the deprecation of African knowledge, as epistemicide, to the violence of colonialisation. Endogenous knowledge was seen under colonialism as inferior and primitive. The argument is that it remains ignored both in the Global North and within Africa itself. African education retains "epistemological xenophilia and knowledge dependency”, Nyamnjoh (2012, 143) suggests. Scholars try to make sense of local problems through the Global North's knowledge system, rather than develop their own theory (Andrews and Okpanachi 2012). In this context, access to the current scholarly publishing system which is founded on the knowledge systems of the Global North is not the central issue; indeed, attempts to participate in it on unequal terms reflects intellectual domination. It is also true that seeing African research as beset by barriers, as in the country deficit model, tends to assume that the model of research practised in the Global North is the right and only one, since it is the failure to have an equivalent research governance and support that is the focus of the perspective. The cognitive injustices perspective opens up the possibility that how research is governed and practised in Africa might be entirely different. In doing so it also potentially questions whether statements about African research under-performance are even relevant if they are based on publication within a colonialist publishing context.

In the African context, this argument is most recently articulated by Mboa Nkoudou (2016) and Piron, Regulus, and Djiboune Madiba (2016) through identifying eight, inter-related "cognitive injustices" that beset African scholarship. Mboa Nkoudou (2016) identifies both endogenous and exogenous cognitive injustices. Endogenous factors include the continuing neo-colonialism of African education which is directed to reproducing local elites and is based on the assumption that local African knowledge is inferior to the knowledges of the Global North (often this writing is equated with "positivist science"). One manifestation of this would be the way that African universities base tenure on publishing in "international journals" produced in the Global North.

For Mboa Nkoudou (2016), the lack of policy and infrastructure to support research in African countries is a further endogenous, cognitive injustice arising from this sense of inferiority. This leaves African research systems dependent on "western philanthropy" (Andrews and Okpanachi 2012). A further effect of the dependence on ideas originating in the Global North is to alienate African citizenry from research, reinforcing a strong barrier between science and society (Mboa Nkoudou 2016).

Central to exogenous epistemic injustice is the impact of the for-profit scientific publication system. This is 
premised on the purpose of research being to promote economic growth, a perspective found pervasively in policy justifications of open science. But the authors argue that this is an alien model of development because it does not fit Africa's needs. The for-profit publishing system effectively restricts access to the apparatus of scholarly publishing, both to publish and to read.

Ultimately, within this argument, minor reforms to how science works now are not likely to address the underlying issue that African knowledge remains unvalued. Open science is often explained as a return to fundamental principles found in the early centuries of Western science in Europe (e.g. National Academies of Sciences, Engineering and Medicine 2018). This makes the assumption that Western science is the correct model for all knowledge creation. From the cognitive injustices perspective, the whole point is that Western science should not be the only model of epistemology. Indeed, the assumption that the starting point to define open scholarship is a return to the roots of Western science is yet another example of the way alternative epistemologies are negated or subordinated. Just as open access has not evolved in an afro-centric direction (Nwagwu 2013) there is a risk that open scholarship as defined in the Global North will fail to reflect African realities, and so may not therefore bring the hoped-for benefits, despite the often good intentions. Thus Mboa Nkoudou (2016) and Piron, Regulus, and Djiboune Madiba (2016) do see benefits in open science, but only if it is defined as the democratisation of access to science, not if it is understood as a means to accelerate scientific productivity or for economic growth. Thus, it is only open scholarship as defined by some of the "schools" that would help research in the Global South. Okune et al. (2016) argue that: "While OA may provide a means to challenge the hegemony of the global publishing system, it also needs to be part of a broader movement to rethink what constitutes scholarly publication, quality, and the impact in an open networked knowledge environment". The work of OCSDNet begins to create a model of what this might look like in practice, e.g. in terms of ensuring all academic partnerships are equitable and that infrastructures are deliberately constructed to be inclusive (OCSDnet n.d).

\subsection{Problem Statement}

The wave of interest in the concept of open scholarship seems to offer new positive possibilities. Authors such as Albornoz et al. (2018), Raju, Adam, and Powell (2015), Piron, Regulus, and Djiboune Madiba (2016) and OCSDNet (n.d.) have suggested that it offers part of a solution to the low visibility of African scholarship. They emphasise what Fecher and Friesike (2013) would probably refer to as the democratic and public schools of open science. It is highly relevant to addressing weaknesses from the scholarly communication system perspective. In contrast, within the country deficit model open scholarship seems somewhat less relevant. The aim of this paper is to explore the possibilities of open scholarship by examining its ability to address need as defined by local actors in a specific country. Thus this paper has two objectives:

- To analyse librarians' perceptions of the key challenges for researchers in Rwanda.

- To consider whether open scholarship can strengthen Rwandan research.

\section{Research Design}

This paper is based on a pilot project to develop a collaborative research network between University of Sheffield and contacts in key higher education institution (HEI) libraries in Rwanda. The focus of this study was to build up a picture of conditions for research in the country as a preliminary step towards co-designing a research agenda around open scholarship. It was sponsored by the Global Challenges Research Fund Quality Related (GCRF-QR) funding directed by the national funding agency, UK Research and Innovation (UKRI), to help consolidate research partnerships in lower and middle-income countries. In following GCRF guidelines on co-developing equitable partnerships (Grieve and Mitchell 2020), we designed the research to be participatory (Bergold and Thomas 2012), around a collaborative workshop format drawing upon sources that promote workshops as data collection methods (Binet et al. 2019; Ørngreen and Levinsen 2017). Four senior librarians with over 40 years' experience between them, from three academic libraries in Rwanda, were invited to participate in the workshop: two from the University of Rwanda and one each from the University of the Lay Adventists of Kigali and the Ruhengeri Institute of Higher Education. All participants were directors of their respective libraries, either at a specific campus or serving the entire institution. Their extensive knowledge of the conditions of research in Rwanda meant they had a very good awareness of the issues we wished to investigate. In quotations below they are referred to as P1P4. The other participant was the representative of an NGO that has worked extensively in the country, Information Training and Outreach Centre for Africa (ITOCA), referred to as P5. All participants were invited to the UK and during 
their week-long visit their views were elicited through a range of discussions and rich picture exercises.

In advance of the workshop, the participants were asked to informally gather information in their institutions around the main question of identifying the challenges for research in Rwanda. In keeping with the participatory approach we were using, workshop sessions were split up during their week-long visit, interspersed with other planned activities. In one session the group explored the national context of Rwanda, its history and colonial legacies. In the next, each participant developed a rich picture (Checkland and Scholes 1999), seeking to capture a major aspect of the challenges for research, followed by a discussion exploring the dimensions of the issues and connections between them. In adopting this participatory format, we were inspired by the use of rich pictures to elicit tacit knowledge about complex problem contexts (e.g. Booton 2018; Walker, Steinfort, and Maqsood 2014). There were then extensive discussions orientated around a public workshop on the theme of open scholarship in Africa held at University of Sheffield where the participants constituted a key panel on "Developing Capacity for Open Scholarship in Rwanda". Future project ideas were discussed in another session and reflections on the entire workshop process were also collected in a focus group at the end of the week. The workshop activities generated $12 \mathrm{~h}$ of audio recordings and extensive verbatim notes. This extensive corpus of in-depth material placed the researchers in a strong position to produce an in-depth analysis.

Adopting a qualitative, inductive analysis approach (Thomas 2006), these were analysed by each author separately through re-reading notes, listening through the recordings and making new transcriptions. Sets of notes were then shared and discussed. The authors then worked together on the creation of tabular comparisons of the data. Extensive discussions between the two authors sought to identify the main themes among the challenges identified. We concluded in identifying six primary themes among the challenges, namely: researcher position, costs, national and institutional support infrastructure, skills and access to content. In order to explore the relationship between these we decided to map the themes and their sub-themes to a simple research life cycle model (idea generation/data collection and analysis/dissemination) (Grigorov et al. 2016). At a later point we further sub-divided aspects of the life cycle, with an emphasis on issues relating to content appropriate to the group as librarians. The results are presented in Table 1 below, with an elaboration offered in the text that follows.

\subsection{The Rwandan Context}

Rwanda, the setting for the study, is an East Central African country of about 11 million inhabitants, $43 \%$ under the age of 15 . At the end of the nineteenth century it became a German colony, then a Belgian colony. It gained independence in 1962. It has had a difficult recent history, notably touched by civil war and the genocide in 1994.

Kinyarwanda is the first language of most Rawandans (Samuelson and Freedman 2010). It remains a largely oral culture (Ruterana 2014). In 2008 the government shifted the medium of education from French to English, officially because of the potential economic benefits, but also for political purposes. Not surprisingly, there were many challenges with this sharp shift of policy, including for university students (Kagwesage 2013).

Rwanda remains an agrarian economy. Yet, it did see a threefold growth in per capita income since the 1990s (World Bank 2019). The percentage of people living in poverty fell from 77.2 to $55.5 \%$. Ambitious plans for the country were encapsulated in the Rwanda vision 2020, with a target of becoming middle-income status by 2020. The development agenda remains "vast" (World Bank 2019, ix). Access and quality of basic education remain one of the issues limiting the country's development (World Bank 2019).

The country has $40 \mathrm{HE}$ institutions (three public and the others private) with around 90,000 total students, about $8 \%$ of the age-qualified youth (Republic of Rwanda 2018). The main university is the University of Rwanda, the result of a merger of other institutions in 2013 (Uwamwezi 2017). A recent report on Rwandan institutions gives a sense of the status of the university sector (Higher Education Council: Republic of Rwanda 2016):

- Only 34\% of institutions had more than 10,000 books in the library; only $38 \%$ added more than 1000 books to their collection during 2014.

- Only $76 \%$ had any international journals; only $59 \%$ have e-journals.

- Only $62 \%$ of HEIs had faculty with a PhD; only $41 \%$ had faculty who had published papers at a national or international conference.

- $\quad$ The average student: computer ratio is 1:0.15.

\section{Results: Challenges for Research in Rwanda}

Table 1 presents the participants' responses to identifying the challenges for research in Rwanda, consisting of five 


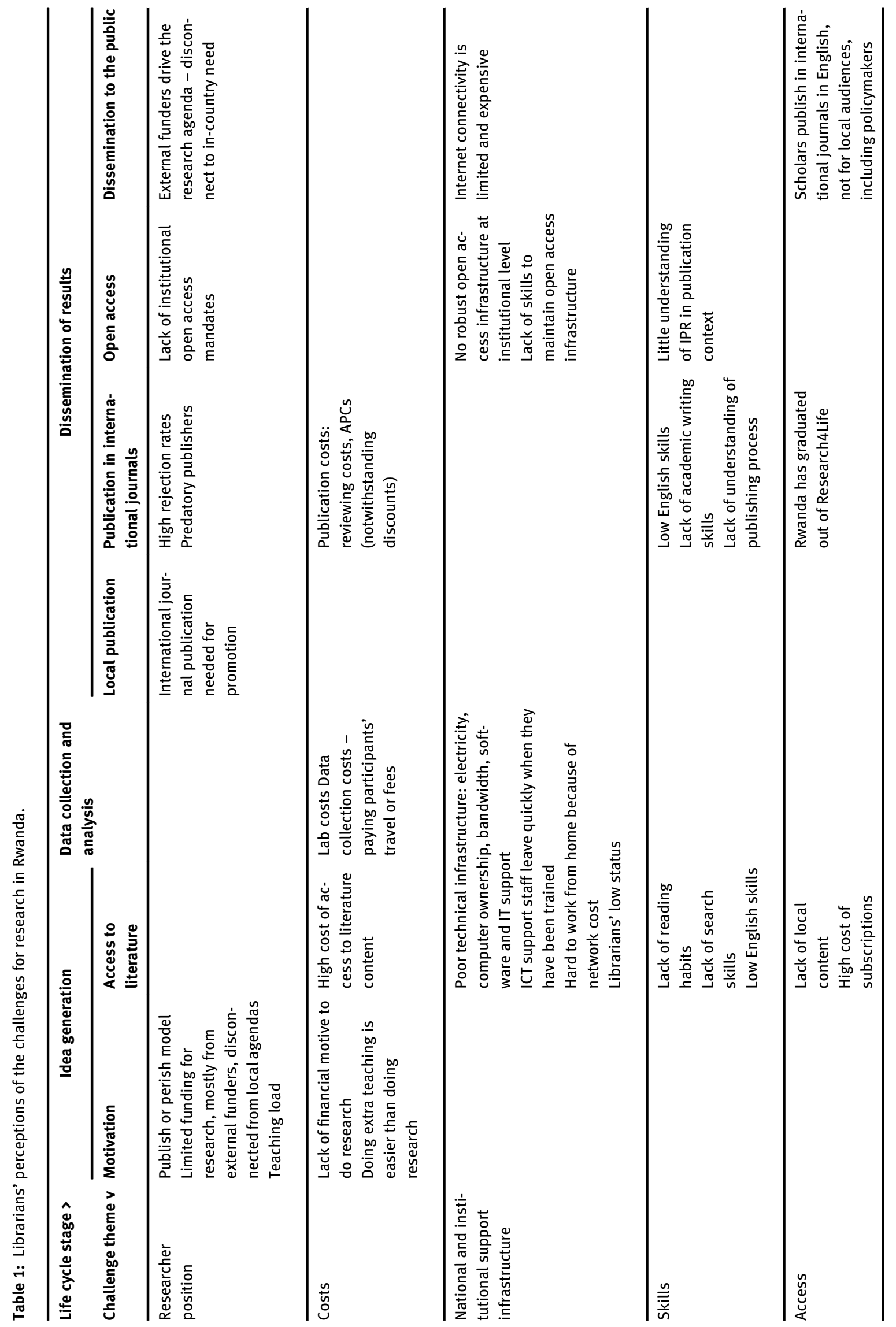


themes mapped to a simple research life cycle model. The first theme revolved around the challenges for the researcher ("Researcher position" in Table 1). Central to this was a "publish or perish" model in which the motivation to undertake research was to gain funding, build reputation and publish in international journals.

When they arrive at the university, when they are a lecturer, you are told by all the senior ones that 'the motto here is publish or perish'. So that's what is inculcated in them right from the beginning. (P5)

But this was highly problematic because research funding is very competitive with success rates at $2-5 \%$. It also skewed research towards quite a narrow research agenda, so that $70 \%$ of publications came from just one sector, namely, health. The limited funding available came from external funders, so they drove agendas, not researcher interest or in-country need.

External funders drive the research agenda. So the research agenda is not yours. You are going to write that [proposal] according to what the researcher is willing to fund, so you tell them what they want to hear and therefore then you will be accepted and you are likely to get some funding. It's driven from outside. (P5)

National level funding was "non-existent" (P1). Participants felt strongly that external funders were not aware enough of in-country needs. The result was a disconnection between research and policy. This was further reinforced by funders' preference for publication in international journals that local policymakers would never read (not least because they often did not read English).

Teaching loads made doing any research difficult. Most contracts stated that $50 \%$ of time was for teaching (30\% research; 20\% administration). But class sizes were very large, so that in reality there was little time for research. Getting published was also difficult, because again rejection rates were experienced as high, a problem participants attributed to researchers' poor skills in writing in English. Scholars' desperation to get published made them vulnerable to predatory publishing.

The second challenge theme was the financial issue ("Costs" in Table 1). As one participant stated, "Every researcher needs money for a better life" (P2) and this was in conflict with the many costs of research. In a fundamental way it seemed that the basic right to earn money to support a good life was an obstacle for making the commitment to research. She said that "so when you get money [from funders] you do everything but when you are hungry you stay at home." Salaries were low and to supplement them it was common for academics to do extra teaching at another institution.
It's easier to get a part-time lectureship in another university rather than investing your time in research. Research consumes a lot of time and the outcome also is not very clear (P1).

There was no shortage of such teaching work, but it meant academics were "weighed down by teaching high numbers of students" (P5) diminishing the time they had to undertake research. At the same time there was a strong sense of the many expenses throughout the research life cycle: subscription costs, lab costs, data collection costs and later publication costs, such as for translation and proofreading and for Article Processing Charges. "Getting the best results from research" required money (P2).

A third challenge theme was the infrastructure, including ICTs ("National and institutional support infrastructure" in Table 1). At both national and institutional levels there were issues with basic electricity supply, computer access and ownership, bandwidth, software and IT support. There were not enough computer labs; not all researchers have computers at home because of the expense of home Internet. Once IT support staffs are trained they tend to leave to better paid jobs in other sectors. There was also a sense that the skills to maintain an open access infrastructure were lacking within institutions. There was a lack of OA policy at an institutional level as well as infrastructure.

Fourthly, another challenge was researchers' skills ("Skills" in Table 1). Researchers lacked skills across a range of critical areas, including in writing, particularly in English, but also in searching for information and understanding the publishing process. One underlying factor that came out strongly was around language. Rwandan culture is oral, and it is this that gives rise to a lack of a reading culture. One participant quoted the customary saying "if you want to hide something, write it down" (P2). Similarly, another said that Rwandans "only read because they are forced to" (P3) and that "We really have a problem of changing our attitude and becoming real readers, effective readers" (P3).

So the oral tradition, I think, is another burden on the academician. To spend time reading, reading is time-consuming and sometimes for some literature, it requires concentration. So, there are many things which cause ... in their home, in their houses, there is no other room because there are many people there, you can't read. (P3)

Quiet space to read seems to be lacking. Most day-to-day interactions are based on Kinyarwanda but this is not used much in education or research. The driver to publish research results in English language international journals effectively makes results inaccessible, because the public 
do not want to read and English is not the natural language of thinking - quite apart from the issue of gaining access to such content. This was one way that research was disconnected from citizens and policymakers: "Few existing materials available are in a language that can be decoded" (P1). To further complicate matters many Rwandans had learned French as a second language; the introduction of English as a language for teaching or publication is relatively recent. Like many non-native English speaking researchers they had to translate their ideas into English for publication in international journals, creating one more hurdle for the researcher to negotiate. Getting work reviewed for language was yet one more cost.

The fifth challenge theme was accessing content ("Access" in Table 1). Content from international journals was perceived to be expensive. Researchers often had to try and find money for journal subscriptions themselves. Research4Life had been very useful, but the publishers now consider Rwanda's GDP to have risen to the level that it should be able to pay for content. In reality they have not been able to do that, so full text access has been lost. Government and consortia efforts to acquire content had failed. So, there was a lack of access to key material for scholars. Often they had to pay for subscriptions themselves. Equally local content about Rwanda was lacking, making it harder to establish a baseline of knowledge on which to build research: "Local content on Rwanda is almost non-existent”, stated one participant (P1). The local publishing industry was hardly developed. Many materials used in learning were not adapted to the local context, because they were produced outside the country. Library collections focussed on printed material; there were problems collecting and organising local cultural materials. Researchers were not motivated to report results in ways to have an impact on policy.

\subsection{Discussion}

The senior librarians' perceptions of the challenges in the Rwandan research environment - addressing our first research question - revolve around the multiple, day to day issues facing the researcher at an individual level, and the practice of research at a more systemic level. Their views reveal that a major defining aspect of research in Rwanda is the researcher being put under pressure to gain external funding and publish internationally, in a context where funding is scarce and competition to publish intense. The issue of costs captures the very material barriers to research that exists throughout the research life cycle. Infrastructure has many inadequacies compared to that enjoyed by researchers in the Global North. The skills base is again perceived to be relatively poor. The issue of language points to the complex tangle of disadvantage under which scholars in Rwanda work, again at each step in the research process. Access to content also remains a challenge. Echoes of similar concerns can be found in accounts in other African countries, e.g. Nigeria (Egwunyenga 2008; Olukoju 2004) and Tanzania (Fussy 2018).

At the more systemic level, the librarians' views emphasised the way that the "normal" of a Global North research environment does not exist in their context: there is very limited national government funding or governance of research; universities do not prioritise research; pay is poor; what is considered taken for granted technical infrastructure in the Global North is not available; the wider culture is oral rather than written. Therefore, the usual premises about how research works that we might hold in the Global North also do not pertain. At every step the researcher is hampered compared to their counterparts in more privileged research environments. Similar views about research environments in Africa are to be found in the literature (e.g. Arvanitis and Mouton 2019).

Reflecting specifically on information and librarianship issues, it follows from the orality of culture that librarianship as a practice of the written cultures of the Global North has relatively low social status. Lack of funds, the high cost of international journals and the failure of open access policy and infrastructure mean that access to content was difficult, undermining the librarian's role further. Temporary access via Research4Life had given the Rwandan librarians status, but when this disappeared they again were left in an ineffectual position, they said. In addition, given the profession's low status it is hard to attract high quality staff.

We could see the librarians' perceptions as fitting quite strongly the country deficit perspective identified in the literature review, recognising the role of weak researcher motivation and support, and poor research infrastructure. There are strong echoes of studies such as those of Atuahene (2011), Fussy (2018), and Ngongalah et al. (2019) that highlight the many barriers to research in sub-Saharan Africa, despite the growing emphasis in policy on building knowledge economies (Arvanitis and Mouton 2019). None of these barriers constitute an absolute divide with the Global North, but as Bezuidenhout et al. (2017) make clear, the accumulation of small, mundane hurdles add up to a critical disadvantage. A particular emphasis in the Rwandan librarians' account is given to the financial issue, which brings home the basic material barrier to undertaking research. In a low income country the many small costs of research are set against low financial rewards and 
funding for research. The complexities of the language issue also point to underlying, intractable cultural issues.

The participants were certainly aware of the inequities of the scholarly communication system, another perspective brought out in our literature review. As librarians, though, they were in the position of seeking to promote access to international literature and publishing within that system. There was less awareness of the kind of trenchant analysis offered from the third perspective in our literature review, that of epistemic injustice. The comments on the control of the agenda by foreign agencies disconnected from in-country need and policy, and the stress on publishing in international journals rather than local dissemination of knowledge, hint strongly at awareness of a continuing neo-colonialist agenda. However, there was less sense that there might be potential for a different model of scholarship and scholarly communication for Africa, as being developed by commentators inOCSDNet (n.d).

By definition, librarians' role is to promote access to content within the existing system of publishing resources. This can be seen as making it inherently hard for them to recognise or articulate the more fundamental epistemic injustices perspective, because there is considerable investment in the current publishing system. Indeed, any African library's attempts to promote literacy are in danger of being seen as supporting linguistic imperialism, as Parry's (2011) work explores. Literacy is often seen as a "good thing" for development, but if local culture is oral, promoting literacy is effectively also to deprecate local culture. It is easy to come to see oral culture as a "burden" if it is a barrier to creating a reading culture. Libraries give people access to knowledge, but if it is only in the form of written texts then it is at odds with an oral culture, even more so if most books are actually in English. The very notion of a library potentially carries with it the cultural assumptions of the Global North. So there are potential dilemmas for librarians embedded as they are in existing institutions of knowledge production if they seek to promote endogenous ways of knowing. Nevertheless, the concept of African librarianship could be a starting point for developing a system of knowledge production based on radically different epistemologies, rather than those of the Global North (Tise and Raju 2015). African libraries have a mandate to collect and promote indigenous knowledge (Moahi 2012) and an important potential role in ensuring the survival of local languages (Ngulube 2012).

Our second research question was about whether open access and the broader concept of open scholarship have potential to improve the condition of Rwandan research. The librarians were very aware of the potential but actual failure of open access. In theory, open, costless access to publications would enable researchers in Rwanda to stay up to date with the literature. Indirectly, it would also improve the status of librarianship, because more content could be provided. Green open access also makes it possible in theory for researchers in Rwanda to publish their work in visible ways.

However, in reality, scholars in Rwanda are still struggling to access content. This is partly because of a lack of search skills. Further, a green open access infrastructure barely exists, partly, our participants said, because of a skills deficit and also because institutions fail to mandate deposit. Rwandan scholars can gain discounts on APCs, but in local terms the cost is still prohibitive. Thus, scholars in Rwanda do not have easy access to reading or publishing in international journals. Yet, according to our participants, tenure is premised on this form of publication. As Nwagwu (2013) argues, open access has not evolved in a direction that fits the needs of Africa. This aspect of open scholarship seems to be failing and the way it has failed may also give us clues to the problems that could recur in how open scholarship as a broader concept evolves.

Turning to broader features of open scholarship, beyond open access to publications, as outlined in the literature review, openness of data would enable scholars in Rwanda the possibility to participate in global research networks. Similarly, access to open software would allow researchers to use the same analytic methodologies as researchers in the Global North. However, if there is still great relative under resourcing in the research environment then that would prevent it being a truly level playing field. One obvious aspect of this is that the technological infrastructure might still make it difficult in practice to use open data or code on equal terms (Bezuidenhout et al. 2017). Scholars would often be working on relatively old computers with low bandwidth. According to our participants, Rwandan researchers find it hard to work from home because of the cost of an individual Internet connection. It is also hard to find the headspace to read at home. Thus, in small but cumulatively very significant ways such issues place the Rwandan scholar at a critical disadvantage, even if certain types of openness are achievable (cf. Herb and Schöpfel 2018). A concept of open scholarship that does not rest on the assumption of the conditions for research in the Global North as normal is needed in Rwanda. But it is not just about technical infrastructure - and so cannot simply be offered through technical fixes. Much more broadly than this, it is that the whole environment for research is relatively unfavourable. Funding is scarcer, teaching workloads are heavier and the level of digital skills lower than in the Global North. The whole context for research in 
Rwanda makes it hard to compete with scholars operating in much more favourable circumstances in the Global North. Open scholarship as usually defined does not seem to address these disadvantages. Indeed, it could be that opening up data, for example, could be far more beneficial to authors in the Global North who have the infrastructure to use this effectively than for scholars in Rwanda (Bezuidenhout et al. 2017; Serwadda et al. 2018).

More fundamentally, most current conceptions of open scholarship developed in the Global North (Fecher and Friesike 2013) fail to challenge inequities in the current system such as the dominance of English language publishing or seek to open up to alternative epistemologies. The epistemic injustices perspective, as promoted by Piron, Regulus, and Djiboune Madiba (2016), implies a different model of open scholarship. It gives emphasis to some aspects of the open agenda such as breaking down the barrier between science and citizens as in Fecher and Friesike's (2013) "public school" of open science, while simultaneously, through privileging local languages and local knowledges, redefining what science means. Similarly, the OCSDNet manifesto begins to define what an inclusive open scholarship should look like, in keeping with open development agendas that are sensitive to context (OCSDNet n.d). These initiatives go beyond the schools defined in Fecher and Friesike's (2013) typology by seeking to make scholarship more locally relevant and accessible. This is not necessarily utopian but to truly work would require many significant shifts. Issues that we have dubbed "in-country deficit", and which were mainly highlighted by our participants, would still have to be addressed to strengthen the infrastructure of the research environment. However, a fundamental shift in thinking about the practice of research, its purpose and outcomes, would be needed, placing more emphasis on the notions of collaboration and participation implicit in open scholarship. Critically, these new practices would need to give greater status to publication in local journals, in local languages. This would increase local engagement with research by policymakers and citizens. Rather than forcing researchers to operate within the existing scholarly communication system, always working at a relative disadvantage, there would be a need to commit to a very different model of scholarship.

\section{Conclusion}

This paper has examined the potential of open scholarship to address the challenges of research in the Global South, specifically in Rwanda. It was based on a rich data set developed working intensively with three senior librarians from the country and a fourth expert with substantial knowledge of the country. It has made three contributions to the Library and Information Sciences (LIS) literature. Firstly, it has identified three distinct perspectives in the literature on these research challenges, namely, the incountry deficit, scholarly communications system and cognitive injustices perspectives. Secondly, it has explored senior librarians' views on what inhibits research in their country, specifically identifying five distinct but interconnected challenge themes. Thirdly, it has demonstrated in the Rwandan context how an accumulation of small, relative disadvantages can create a critical scholarship divide. It then weighed up how far open scholarship offers a solution, concluding that, in its current manifestation as a concept largely conceived in the Global North, it is relevant, but only a very small part of a way, to addressing the challenges of research in countries such as Rwanda. The paper then argues that the impact of conditions for research in the Global South needs to be more central to the definition of open scholarship.

The authors of this paper are conscious that there is a strong tradition in the thinking of the Global North to see Africa as always a problem - beset by war, famine, disease and corruption - and that our own analysis seems to reproduce such discourses. Indeed, it is a methodological limitation of the paper that our conversation with the Rwandan librarians was organised around asking them to talk about research challenges. This framed the entire discussion premised on a narrative of challenge. Future research, as well as expanding the range of participants to include researchers themselves, should seek ways to uncover different starting points for the discussion beyond an assumption of challenge, perhaps around the potential to integrate endogenous knowledge together with traditional western science. In addition, we would argue that the challenges that Rwandan research has are in a number of senses something that the Global North is implicated in too. Firstly, the basic defining societal context of research is shaped by historic colonialism and by forces that continue to give those in the Global North a privileged life at the cost of exploiting countries like Rwanda. The Global North had a big hand in creating the "problems" of Africa and continues to benefit from systems that sustain those issues. More specifically, scholars in UK and USA continue to have a huge advantage from their positions as editors and reviewers influencing the international publishing system, as well as simply through having the privilege to write in their own language.

The challenges identified in Rwanda are ours too in the Global North for a second reason. The white privilege of 
writing and reading in English also suppresses and disconnects the Global North from alternative ideas and ways of knowing. Effectively, scholars in the Global North should recognise themselves as existing within a Web of Science filter bubble. Sources for alternative ideas rarely get published within the indexed journals, including those reflecting alternative ways of thinking rooted in the Global South. Ideas premised on traditions of thought from the Global North are consistently privileged. Scholars prefer to cite ideas in journals with impact, but within a flawed system of measuring impact this effectively excludes much human knowledge. Scholars in the Global North are epistemically impoverished by their denial of the value of other forms of knowledge in the way this system privileges "scientific knowledge" over other forms of knowing. If our own education system still needs decolonising, this partly explains why.

If scholars in the Global North recognise the value of the epistemic injustices perspective, it could be one factor leading to a shift that would echo positively in countries such as Rwanda. If authors, editors and reviewers in the Global North sought to read and recognise new epistemologies, they would be forced out of the Web of Science filter bubble. In this context African scholars would have a relative advantage in terms of language and understanding since they have access to a reservoir of endogenous knowledge. Issues of relative disadvantage in infrastructure would have less weight because it would be recognised that the alternative voices need to be incorporated and it would be recognised that it is in everyone's interest to overcome inequalities. However, there would still need to be fundamental shifts in resourcing of research in subSaharan Africa to create anything approximating a level playing field.

\section{References}

Albornoz, D., M. Huang, I. Martin, M. Mateus, A. Touré, and L. Chan. 2018. Framing Power: Tracing Key Discourses in Open Science Policies. Toronto, Canada: ELPUB 2018, https://doi.org/10. 4000/proceedings.elpub.2018.23.

Andrews, N., and E. Okpanachi. 2012. "Trends of Epistemic Oppression and Academic Dependency in Africa's Development: The Need for a New Intellectual Path." Journal of Pan African Studies 5 (8): 85-104.

Arvanitis, R., and J. Mouton. 2019. "Observing and Funding African Research. Centre Population et développement, Université Paris Descartes." Working paper. https://www.ceped.org/IMG/pdf/ wp43.pdf (accessed December 10, 2020).

Atuahene, F. 2011. "Re-thinking the Missing Mission of Higher Education: An Anatomy of the Research Challenge of African Universities." Journal of Asian and African studies 46 (4): 321-41.
Bai, Y. 2018. "Has the Global South Become a Playground for Western Scholars in Information and Communication Technologies for Development? Evidence from a Three-Journal Analysis." Scientometrics 116 (3): 2139-53.

Beaudry, C., J. Mouton, and H. Prozesky. 2018. The Next Generation of Scientists in Africa. Cape Town: African Minds.

Bergold, J., and S. Thomas. 2012. "Participatory Research Methods: A Methodological Approach in Motion.” Forum Qualitative Sozialforschung/Forum for Qualitative Social Research 13 (1), https://doi.org/10.17169/fqs-13.1.1801.

Bezuidenhout, L. 2019. "To Share or Not to Share: Incentivizing Data Sharing in Life Science Communities." Developing World Bioethics 19 (1): 18-24.

Bezuidenhout, L., and E. Chakauya. 2018. "Hidden Concerns of Sharing Research Data by Low/middle-Income Country Scientists." Global Bioethics 29 (1): 39-54.

Bezuidenhout, L. M., S. Leonelli, A. H. Kelly, and Brian. Rappert. 2017. "Beyond the Digital Divide: Towards a Situated Approach to Open Data." Science and Public Policy 44 (4): 464-75.

Binet, A., V. Gavin, L. Carroll, and M. Arcaya. 2019. "Designing and Facilitating Collaborative Research Design and Data Analysis Workshops: Lessons Learned in the Healthy Neighborhoods Study." International Journal of Environmental Research and Public Health 16 (3): 324.

Booton, C. M. 2018. "Using Rich Pictures to Verify, Contradict, or Enhance Verbal Data." The Qualitative Report 23 (11): 2835-49.

Borgman, C. L. 2012. "The Conundrum of Sharing Research Data." Journal of the American Society for Information Science and Technology 63 (6): 1059-78.

Boshoff, N. 2009. "Neo-colonialism and Research Collaboration in Central Africa." Scientometrics 81 (2): 413-34.

Canagarajah, A. S. 2002. A Geopolitics of Academic Writing. Pittsburgh (PA): University of Pittsburgh Press.

Checkland, P., and J. Scholes. 1999. Soft Systems Methodology: A 30-year Retrospective, new ed. Chichester: Wiley.

Chiware, E. R., and D. A. Becker. 2018. "Research Data Management Services in Southern Africa: A Readiness Survey of Academic and Research Libraries." African Journal of Library, Archives and Information Science 28 (1): 1-16.

Collins, C. S., and R. A. Rhoads. 2010. "The World Bank, Support for Universities, and Asymmetrical Power Relations in International Development." Higher Education 59 (2): 181-205.

Dlamini, N. N., and M. Snyman. 2017. "Institutional Repositories in Africa: Obstacles and Challenges." Library Review 66 (6/7): 535-48.

Egwunyenga, E. J. 2008. "Dystrophies and Associated Crises in Research and Academic Publications in Nigerian Universities." The Anthropologist 10 (4): 245-50.

Fecher, B., and S. Friesike. 2013. "Open Science: One Term, Five Schools of Thought.” In Opening Science, edited by S. Bartling, and S. Friesike, 17-47. New York, NY: Springer. Opening Science.

Fonn, S., L. Ayiro, P. Cotton, A. Habib, P. M. F. Mbithi, A. Mtenje, and A. Ezeh. 2018. "Repositioning Africa in Global Knowledge Production." The Lancet 392 (10153): 1163-6.

Fussy, D. S. 2018. "Policy Directions for Promoting University Research in Tanzania." Studies in Higher Education 43 (9): 1573-85.

Grieve, T., and R. Mitchell. 2020. “Promoting Meaningful and Equitable Relationships? Exploring the UK's Global Challenges 
Research Fund (GCRF) Funding Criteria from the Perspectives of African Partners." The European Journal of Development Research 32 (3): 514-28.

Grigorov, I., J. Carvalho, J. Davidson, M. Donnelly, M. Elbaek, G. Franck, and B. Schmidt. 2016. Research Lifecycle Enhanced by an 'Open Science by Default' Workflow. https://www.rri-tools.eu/-/ research-lifecycle-enhanced-by-an-open-science-by-defaultworkflow (accessed December 10, 2020).

Gwynn, S. 2019. Access to Research in the Global South: Reviewing the Evidence. Oxford: INASP. https://www.inasp.info/publications/ access-research-global-south-reviewing-evidence (accessed December 10, 2020).

Herb, U., and J. Schöpfel. 2018. Open Divide: Critical Studies on Open Access. Sacramento (CA): Library Juice Press.

Higher Education Council: Republic of Rwanda. 2016. A Report on the Ranking of Higher Education Institutions in Rwanda. http:// hec.gov.rw/fileadmin/user_upload/DOCUMENTS/Reports/ rwanda-final_validation_report.pdf (accessed December 10, 2020).

Hillyer, R., A. Posada, D. Albornoz, L. Chan, and A. Okune. 2017. "Framing a Situated and Inclusive Open Science: Emerging Lessons from the Open and Collaborative Science in Development Network." In Expanding Perspectives on Open Science: Communities, Cultures and Diversity in Concepts and Practices: Proceedings of the 21st International Conference on Electronic Publishing, edited by L. Chan, and F. Loizdes, 18-32. Amsterdam: IOS Press.

Kagwesage, A. M. 2013. "Coping with English as Language of Instruction in Higher Education in Rwanda." International Journal of Higher Education 2 (2): 1-12.

Lasthiotakis, H., A. Kretz, and C. Sá. 2015. “Open Science Strategies in Research Policies: A Comparative Exploration of Canada, the US and the UK." Policy Futures in Education 13 (8): 968-89.

Levin, N., S. Leonelli, D. Weckowska, D. Castle, and J. Dupré. 2016. "How Do Scientists Define Openness? Exploring the Relationship between Open Science Policies and Research Practice." Bulletin of Science, Technology \& Society 36 (2): 128-41.

Malapela, T. 2017. "Access to Scholarly Research Information in Subsaharan Africa: A Review." Libri 67 (1): 1-13.

Masuzzo, P., and L. Martens. 2017. Do you speak open science? Resources and tips to learn the language (No. e2689v1). Peer) Preprints.

Mboa Nkoudou, T. H. 2016. Les injustices cognitives en Afrique subsaharienne: réflexions sur les causes et les moyens de lutte. Connexion Justice cognitive, libre accès et savoirs locaux: pour une science ouverte juste, au service du développement local durable. https://corpus.ulaval.ca/jspui/bitstream/20.500. 11794/14541/1/Chapitre\%202.pdf (accessed December 10, 2020).

Ministry of Education. Republic of Rwanda. 2018. 2018 Education Statistics. http://197.243.16.104/ mineduc/newweb/ fileadmin/user_upload/pdf_files/2018_Rwanda_Education_ Statistics.pdf (accessed December 10, 2020).

Moahi, K. H. 2012. "Promoting African Indigenous Knowledge in the Knowledge Economy: Exploring the Role of Higher Education and Libraries." Aslib Proceedings: New Information Perspectives 64 (5): 540-54.
Molla, T., and D. Cuthbert. 2018. "Re-imagining Africa as a Knowledge Economy: Premises and Promises of Recent Higher Education Development Initiatives." Journal of Asian and African Studies 53 (2): 250-67.

National Academies of Sciences, Engineering, and Medicine. 2018. Open Science by Design: Realizing a Vision for 21st Century Research. National Academies Press. https://www.ncbi.nlm.nih. gov/books/NBK525417/ (accessed December 10, 2020).

Ngongalah, L. N., N. N. Rawlings, E. N. Wepngong, J. Musisi, C. Ngwayu, and S. Mumah. 2019. "Tackling the Research Capacity Challenge in Africa: An Overview of African-Led Approaches to Strengthen Research Capacity." bioRxiv, 518498.

Ngulube, P. 2012. "Revitalising and Preserving Endangered Indigenous Languages in South Africa through Writing and Publishing." South African Journal of Libraries and Information Science 78 (1): 11-24.

Nwagwu, W. 2013. "Open Access Initiatives in Africa-Structure, Incentives and Disincentives." The Journal of Academic Librarianship 39 (1): 3-10.

Nyamnjoh, F. B. 2012. “'Potted Plants in Greenhouses': A Critical Reflection on the Resilience of Colonial Education in Africa." Journal of Asian and African Studies 47 (2): 129-54.

OCSDNet. n.d. Open Science Manifesto: Towards an Inclusive Open Science for Social and Environmental Well-Being. https:// ocsdnet.org/manifesto/open-science-manifesto/ (accessed December 10, 2020).

Ørngreen, R., and K. Levinsen. 2017. "Workshops as a Research Methodology." Electronic Journal of e-Learning 15 (1): 70-81.

Okune, A., B. Hillyer, D. Albornoz, N. Sambuli, and L. Chan. 2016. "Tackling Inequities in Global Scientific Power Structures." The African Technopolitan 4 (1): 129-31.

Olukoju, A. 2004. "The Crisis of Research and Academic Publishing in Nigerian Universities." Africa Universities in the Twenty-First Century 2: 363-75.

Ondari-Okemwa, E. 2007. "Scholarly Publishing in Sub-saharan Africa in the Twenty-First Century: Challenges and Opportunities." First Monday 12 (10). https://journals.uic.edu/ojs/index.php/fm/ article/view/1966 (accessed December 10, 2020).

Parry, K. 2011. "Libraries in Uganda: Not Just Linguistic Imperialism.” Libri 61 (4): 328-37.

Phillipson, R. 1992. Linguistic Imperialism. London and New York: Routledge.

Piron, F., S. Regulus, and M. S. Djiboune. Madiba. 2016. Justice cognitive, libre accès et savoirs locaux. Pour une science ouverte juste, au service du développement local durable. Quebec: Science et bien commun.

Raju, R., A. Adam, and C. Powell. 2015. "Promoting Open Scholarship in Africa: Benefits and Best Library Practices." Library Trends 64 (1): 136-60.

Ruterana, P. C. 2014. "Reflections on Societal Reading: The Case of Rwanda." Journal of Pan African Studies 8: 174.

Samuelson, B. L., and S. W. Freedman. 2010. "Language Policy, Multilingual Education, and Power in Rwanda." Language Policy 9 (3): 191-215.

Schmidt, B., T. Ross-Hellauer, X. van Edig, and E. C. Moylan. 2018. "Ten Considerations for Open Peer Review." F1000Research 7 (969), https://doi.org/10.12688/f1000research.15334.1. 
Serwadda, D., P. Ndebele, M. K. Grabowski, F. Bajunirwe, and R. K. Wanyenze. 2018. "Open Data Sharing and the Global South-Who Benefits?” Science 359 (6376): 642-3.

Thomas, D. R. 2006. "A General Inductive Approach for Analyzing Qualitative Evaluation Data." American Journal of Evaluation 27 (2): 237-46.

Tise, E. R., and R. Raju. 2015. “African Librarianship: A Relic, a Fallacy, or an Imperative?” Library Trends 64 (1): 3-18.

Uwamwezi, B. 2017. "Academic Libraries: Opportunities and Challenges of Resource Sharing within a Merger." In iConference 2017 Proceedings. https://www.ideals.illinois.edu/handle/ 2142/96725 (accessed December 10, 2020).

Vermeir, K., S. Leonelli, A. S. B. Tariq, S. Sojinu, and A. Ocloo, M. A. I. Khan, and L. Bezuidenhout. 2018. Global Access to
Research Software: The Forgotten Pillar of Open Science Implementation. A Global Young Academy Report. Halle. Global Young Academy, Halle (D).

Vicente-Sáez, R., and C. Martínez-Fuentes. 2018. "Open Science Now: A Systematic Literature Review for an Integrated Definition." Journal of Business Research 88: 428-36.

Walker, D., S. Paul, and T. Maqsood. 2014. "Stakeholder Voices through Rich Pictures." International Journal of Managing Projects in Business 7 (3): 342-61.

World Bank. 2019. Rwanda - Systematic Country Diagnostic. Washington, D.C.: World Bank Group. http://documents. worldbank.org/curated/en/219651563298568286/ Rwanda-Systematic-Country-Diagnostic (accessed December 10, 2020). 